Linda Dwi Rohmadiani dan Rigen Adi Kowara: Tingkat Kawasan Rawan Lebakaran Sebagai Upaya Pencegahan dan Penenggulangan Kebakaran

\title{
TINGKAT RISIKO KAWASAN RAWAN KEBAKARAN SEBAGAI UPAYA PENCEGAHAN DAN PENANGGULANGAN KEBAKARAN
}

\author{
Linda Dwi Rohmadiani ${ }^{1)}$ dan Rigen Adi Kowara ${ }^{1)}$ \\ ${ }^{1)}$ Program Studi Perencanaan Wilayah Dan Kota, Fakultas Teknik Sipil Dan Perencanaan \\ Universitas PGRI Adi Buana Surabaya \\ email: linda@unipasby.ac.id
}

\begin{abstract}
Abstrak
Kecamatan Kebomas merupakan wilayah yang diperuntukkan untuk kawasan permukiman, perdagangan-jasa, pertambangan-migas, industri besar dan menengah. Tren kebakaran di Kawasan Perkotaan Gresik menunjukkan bahwa Kecamatan Kebomas memiliki presentase tertinggi kasus kebakarannya pada tahun 2010-2014 sebesar 43,83\%. Tujuan penelitian ini adalah menganalisis tingkat risiko kebakaran di Kecamatan Kebomas. Metode penelitian ini menggunakan metode penelitian kuantitatif dengan teknik analisis skoring dan Overlay GIS. Teknik pengumpulan data berupa observasi lapangan, dokumentasi dan pengambilan data sekunder. Hasil analisis dapat diketahui bahwa tingkat risiko kebakaran terbagi menjadi dua tingkat risiko yaitu kawasan tingkat risiko sedang sebanyak 13 desa, sedangkan 8 desa adalah kawasan tingkat risiko rendah.
\end{abstract}

Kata kunci: Permen PU No. 20/PRT/M/2009, permukiman, tingkat risiko kebakaran

\begin{abstract}
Kebomas Subdistrict is an area designated for residential, trade-services, mining-oil and gas, large and medium-sized industries. The trend of fires in the Gresik Urban Area shows that Kebomas Subdistrict has the highest percentage of fire cases in 2010-2014 of 43.83\%. The purpose of this study was to analyze the level of fire risk in Kebomas District. This research method uses quantitative research methods with GIS scoring and Overlay analysis techniques. Data collection techniques in the form of field observations, documentation and secondary data retrieval. The results of the analysis can be seen that the level of fire risk is divided into two levels of risk, namely the medium risk level area of 13 villages, while 8 villages are low risk level areas.
\end{abstract}

Keywords : Permen PU No. 20/PRT/M/2009, Settlements, Fire Risk 


\section{PENDAHULUAN}

Kebakaran merupakan proses terbakarnya sesuatu yang menimbulkan bahaya atau mendatangkan bencana. Kebakaran dapat terjadi karena pembakaran, baik melalui proses spontan alami atau karena kelalaian manusia, yang tidak dikendalikan. Berdasarkan penyebabnya, bencana kebakaran dapat dibedakan menjadi tiga jenis, yaitu faktor alami, akibat ulah manusia, atau kombinasi. Bencana kebakaran karena ulah manusia merupakan peristiwa yang terjadi baik sengaja maupun tidak disengaja karena proses teknologi, interaksi manusia terhadap lingkungannya serta interaksi antara manusia itu sendiri yang dapat menimbulkan dampak negatif terhadap kehidupan dan penghidupan masyarakat termasuk kerusakan sarana dan prasarana lainnya yang membawa dampak sosial dan ekonomi (Notohadinegoro, 2006).

Bencana kebakaran di Kabupaten Gresik merupakan bencana lokal. Berdasarkan Peraturan Daerah Kabupaten Gresik Nomor 8 Tahun 2011 tentang Rencana Tata Ruang Wilayah Kabupaten Gresik tahun 2010-2030, Kecamatan Kebomas merupakan wilayah yang diperuntukkan untuk kawasan permukiman, perdagangan-jasa, pertambangan migas, industri besar dan menengah. Kawasan peruntukan industri rumah tangga di Kecamatan Kebomas diantaranya usaha pembuatan tempe, kerupuk, dan kemasan (Anonim, 2011). Dampak yang timbul terhadap wilayah tersebut, yaitu semakin rentan terhadap ancaman bahaya kebakaran karena semakin banyaknya lingkungan bangunan yang menghadirkan target hazards dalam suatu kota. Target hazards adalah fitur tapak yang memiliki hambatan atau gangguan bagi pelaksanaan normal operation. Hambatan dapat berupa jiwa manusia, bangunan, serta kondisi-kondisi lainnya yang dapat memicu terjadinya hambatan dalam pemadaman kebakaran (Indrawan, 2013). Strategi pengembangan kawasan rawan bencana kebakaran yaitu dengan mengelola kawasan yang didukung ketersediaan sarana dan prasarana pencegahan dan penanggulangan kebakaran seperti pos pemadam kebakaran dan hidran (Anonim, 2011).

Tren kebakaran di Perkotaan Gresik menunjukkan Kecamatan Kebomas merupakan kecamatan dengan presentase tertinggi kasus kebakaran tahun 2010-2014 sebesar $43,83 \%$. Berdasarkan data milik UPT. PMK Kabupaten Gresik, bencana kebakaran yang terjadi di Kecamatan Kebomas tahun 2010 hingga tahun 2014 mengalami peningkatan sebesar 544\% dengan jumlah keseluruhan bencana yang terjadi sebanyak 219 kasus kebakaran (RISPK Gresik Kota, 2015).

Melihat berbagai masalah kebakaran yang terjadi, maka diperlukan identifikasi dan analisis risiko bahaya kebakaran untuk mengurangi atau menghilangkan bahaya yang dapat menyebabkan kerugian akibat kebakaran di wilayah penelitian yang terletak di Kecamatan Kebomas Kabupaten Gresik. Tujuan penelitian ini adalah menganalisis risiko kebakaran di Kecamatan Kebomas, meliputi Angka Klasifikasi Risiko Bahaya Kebakaran (ARK), Angka Klasifikasi Konstruksi Risiko Kebakaran (AKK), kepadatan penduduk, Koefisien Dasar Bangunan (KDB), Koefisien Lantai Bangunan (KLB), jarak lokasi sumber air terdekat ke daerah rawan, History kebakaran, aksesbilitas menuju daerah rawan kebakaran, jarak pos PMK eksisting menuju daerah rawan kebakaran dan proporsi luas kawasan terbangun terhadap luas total daerah rawan kebakaran (RISPK Kota Muara Enim, 2011).

Penelitian ini diharapkan dapat menjadi sumber rujukan bagi pemerintah untuk menentukan kebijakan dan arahan dalam penanganan kasus kebakaran di Kecamatan Kebomas.

\section{METODE}

Metode penelitian yang digunakan adalah metode penelitian kuantitatif. Data yang didapat dihimpun, diamati dan diidentifikasi untuk memberikan interpretasi terhadap kawasan risiko kebakaran di Kecamatan Kebomas. Hasil yang didapatkan dari pengamatan akan dianalisis dengan menghitung tingkat risiko 
Linda Dwi Rohmadiani dan Rigen Adi Kowara: Tingkat Kawasan Rawan Lebakaran Sebagai Upaya Pencegahan dan Penenggulangan Kebakaran

kebakaran yang ada di Kecamatan

Kebomas.

Metode pengumpulan data melalui observasi, dokumentasi, dan survei instansi (BPBD, BPS, Bappekab Gresik, Dinas Pemadam Kebakaran dan Dinas PU).

Metode analisis kuantitatif melalui teknik skoring masing-masing variabel sesuai dengan kriteria yang telah ditentukan dan teknik Overlay menggunakan ArcGIS. Besarnya nilai penimbang penentuan tingkat risiko kebakaran pada masingmasing sub variabel dapat dilihat pada Tabel

Tabel 1. Nilai Pembobotan Tingkat Risiko Kebakaran

\begin{tabular}{llccc}
\hline No. & \multicolumn{1}{c}{ Sub Variabel } & Bobot & Skor minimal & Skor maksimal \\
\hline 1. & ARK Daerah Rawan Kebakaran & $10 \%$ & 0,1 & 0,5 \\
2. & AKK Daerah Rawan Kebakaran & $10 \%$ & 0,1 & 0,5 \\
3. & Kepadatan Penduduk Daerah Rawan kebakaran & $10 \%$ & 0,1 & 0,5 \\
4. & $\begin{array}{l}\text { KDB (Koefisien Dasar Bangunan) Daerah } \\
\text { Rawan Kebakaran }\end{array}$ & $15 \%$ & 0,15 & 0,75 \\
5. & $\begin{array}{l}\text { KLB (Koefisien Lantai Bangunan) Daerah } \\
\text { Rawan Kebakaran }\end{array}$ & $10 \%$ & 0,1 & 0,5 \\
6. & $\begin{array}{l}\text { Jarak Lokasi Sumber Air Terdekat Ke Daerah } \\
\text { Rawan Kebakaran }\end{array}$ & $10 \%$ & 0,1 & 0,5 \\
7. & History Kebakaran & $10 \%$ & 0,1 & 0,5 \\
8. & $\begin{array}{l}\text { Aksesibilitas Menuju Daerah Rawan Kebakaran } \\
\text { 9. }\end{array}$ & $10 \%$ & 0,1 & 0,5 \\
$\quad \begin{array}{l}\text { Rarak Pos PMK Eksisting menuju Daerah } \\
\text { 10. }\end{array}$ & $10 \%$ & 0,1 & 0,5 \\
& $\begin{array}{l}\text { Proporsi Luas Kawasan Terbangun Terhadap } \\
\text { Luas Total Daerah Rawan Kebakaran }\end{array}$ & $5 \%$ & 0,05 & 0,25 \\
\hline
\end{tabular}

Sumber: RISPK Muara Enim, 2011

Nilai tingkat risiko bencana kebakaran dalam penelitian ini dibagi menjadi tiga kelas yaitu tingkat risiko rendah, sedang, dan tinggi. Untuk lebih jelasnya dapat dilihat pada Tabel 2.

Tabel 2. Pembagian Kelas Tingkat Risiko Kebakaran

\begin{tabular}{clc}
\hline No. & \multicolumn{1}{c}{$\begin{array}{c}\text { Tingkat } \\
\text { Risiko }\end{array}$} & Skor Total \\
\hline 1. & Rendah & $1-2,33$ \\
2. & Sedang & $2,34-3,67$ \\
3. & Tinggi & $3,68-5$ \\
\hline
\end{tabular}

Sumber: Hasil Analisis, 2016

3. HASIL DAN PEMBAHASAN

a. Analisis Risiko Kebakaran

1) Angka Klasifikasi Risiko Bahaya Kebakaran (ARK)

Hasil analisis ARK menunjukkan bahwa 9 desa termasuk kategori risiko kebakaran rawan, 11 desa kategori tinggi dan 1 desa kategori sangat rendah.
Desa/kelurahan di Kecamatan Kebomas yang merupakan kawasan dengan risiko kebakaran rawan, seperti sepanjang koridor Jalan Mayjen Sungkono yang melewati Desa Sekarkurung terdapat perumahan, pertokoan, dan pabrik pupuk. Koridor Jalan Darmo Sugondo yang melewati Desa Karangkiring, Desa Segoromadu, Kelurahan Indro, dan Kelurahan Tenggulunan terdapat permukiman dan industri kayu. Koridor Jalan Veteran dan Jalan Dr.Wahidin Sudirohusodo yang melewati Kelurahan Gending, Kelurahan Ngargosari dan Desa Giri terdapat banyak industri dan permukiman. Jika diamati kawasan-kawasan tersebut merupakan kawasan hunian, perdagangan-jasa, dan industri, dimana kuantitas dan kandungan bahan mudah terbakarnya sangat tinggi. Peta analisis Angka Klasifikasi Risiko Kebakaran (ARK) di Kecamatan Kebomas dapat dilihat pada Gambar 1. 


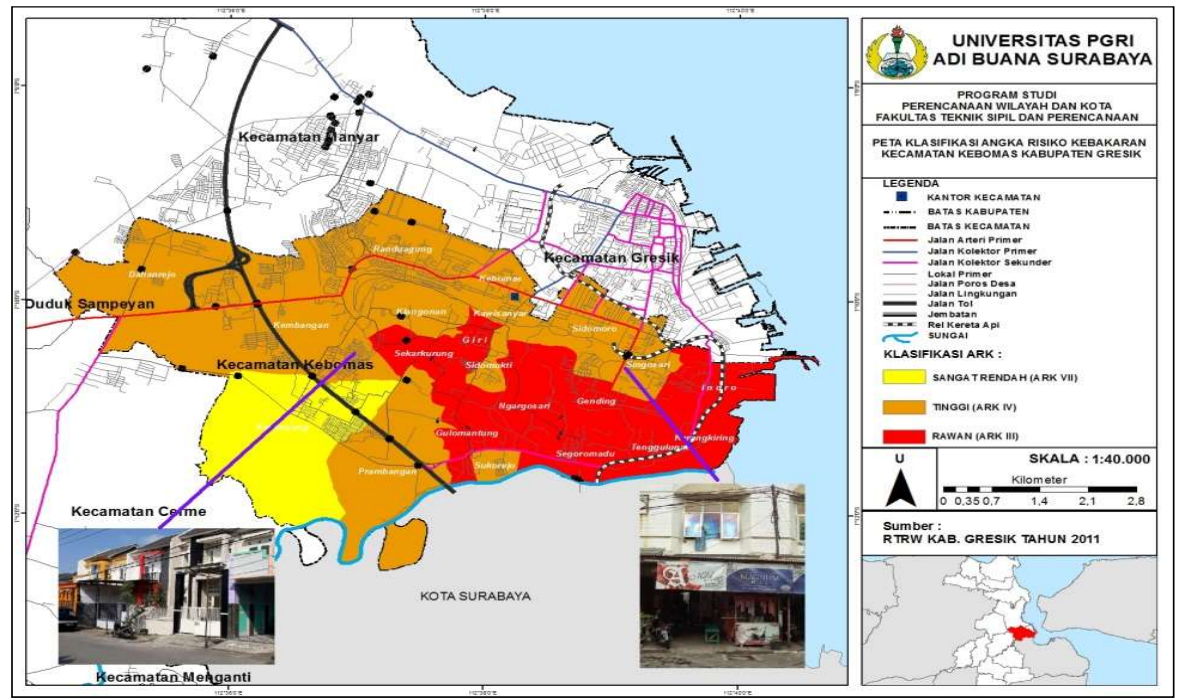

Gambar 1. Peta Analisis Angka Klasifikasi Risiko Kebakaran (ARK) di Kecamatan Kebomas Tahun 2017

\section{2) Angka Klasifikasi Konstruksi Risiko \\ Kebakaran (AKK)}

Berdasarkan hasil analisis AKK di

Kecamatan Kebomas merupakan kawasan dengan risiko kebakaran rendah untuk bangunan dengan konstruksi Tipe I (kontruksi tahan api) berupa bangunan yang dibuat dengan bahan tahan api (beton, bata, dan lain-lain dengan bahan logam yang dilindungi) dengan struktur yang sedemikian rupa hingga tahan api. Rata-rata bangunan di kawasan tersebut adalah bangunan modern dengan bahan tembok. Hasil penelitian ini sesuai dengan penelitian Pradipta (2016) mengungkapkan bahwa bahan komponen struktur utama gedung yang secara keseluruhan menggunakan bahan beton bertulang yang direkatkan dengan adukan semen dapat mencegah penjalaran api pada permukaan, sehingga risiko bencana kebakaran dapat dicegah. Lebih jelasnya dapat dilihat pada Gambar 2.

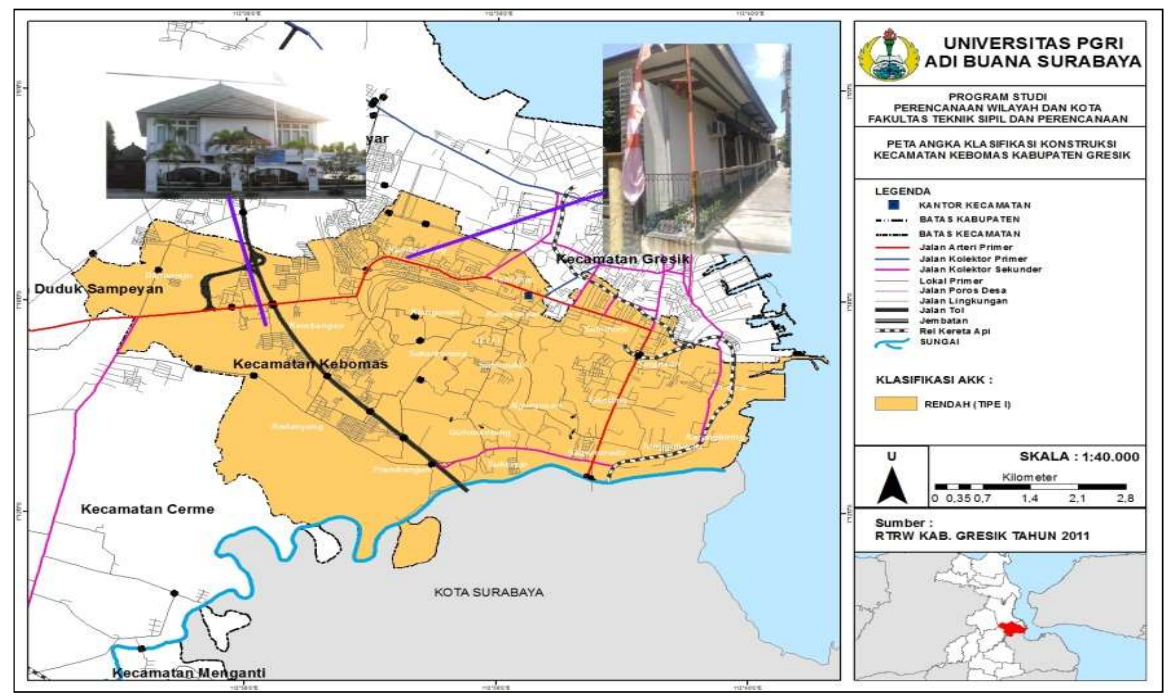

Gambar 2. Peta Analisis Angka Klasifikasi Konstruksi Risiko Kebakaran (AKK) di Kecamatan Kebomas Tahun 2017 


\section{3) Kepadatan Penduduk}

Tingginya kepadatan penduduk dalam suatu wilayah dapat menjadikan suatu indikasi akan tingginya aktivitas yang ada di dalamnya. Tingginya aktivitas penduduk akan suatu wilayah akan berpotensi dalam memicu terjadinya kebakaran yang semakin tinggi pula. Dapat dikatakan bahwa kepadatan penduduk menimbulkan kecenderungan yang berbanding lurus dengan munculnya kejadian kebakaran dimana kejadian kebakaran dapat disebabkan oleh kelalaian manusia (Dwijayanti, 2008).

Kecamatan Kebomas memiliki total kepadatan penduduk sebesar 34,50 jiwa/ha atau sebesar $10 \%$ dari kepadatan penduduk di Kabupaten Gresik. Kepadatan penduduk tinggi dan sedang di Kecamatan Kebomas masing-masing hanya 1 desa/kelurahan, yaitu Desa Giri sebesar 233,11 jiwa/ha $(19 \%)$ dan Kelurahan Singosari sebesar 155,06 jiwa/ha (13\%). Desa/kelurahan dengan kepadatan penduduk rendah masih banyak tersebar di Kecamatan Kebomas mencapai 19 desa/kelurahan dari total 21 desa/kelurahan di Kecamatan Kebomas.

Hasil analisis penelitian ini tidak sejalan dengan penelitian Widyantoro (2016), yang mengungkapkan bahwa permukiman dengan kepadatan penduduk yang tinggi termasuk pada Zona A dimana lokasi dengan tingkat risiko tinggi bencana kebakaran. Lebih jelasnya dapat dilihat pada Gambar 3.

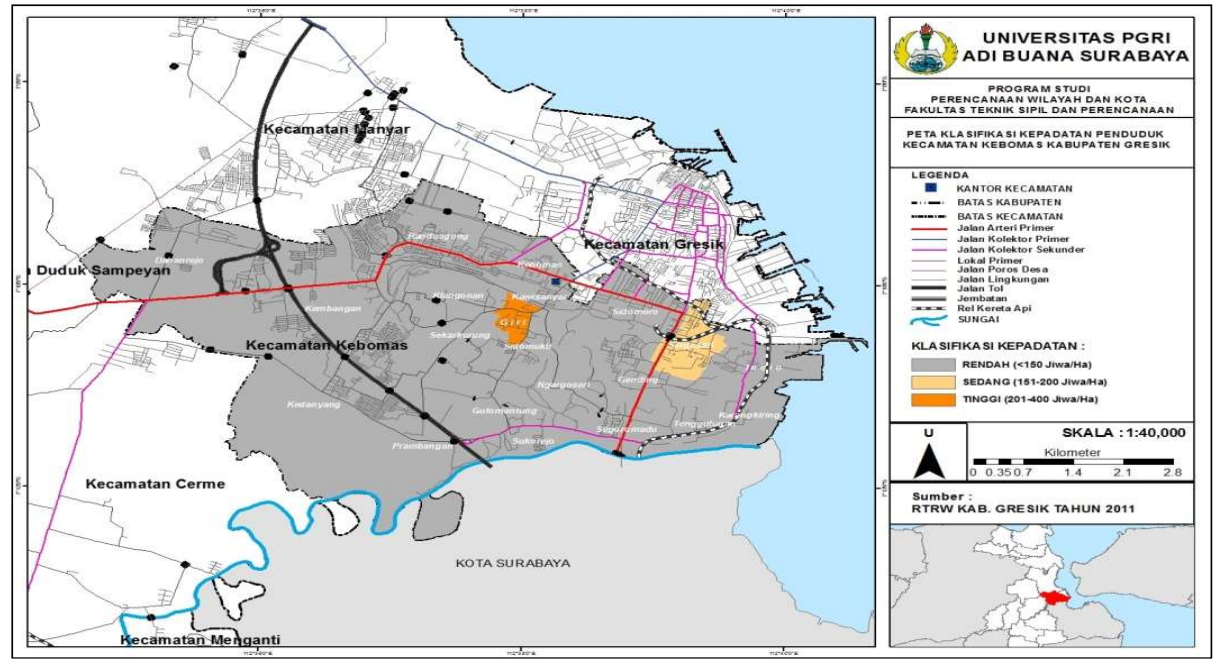

Gambar 3. Peta Analisis Kepadatan Penduduk di Kecamatan Kebomas Tahun 2017

\section{4) Koefisien Dasar Bangunan (KDB)}

Hasil analisis menunjukkan sebagian

besar desa/kelurahan di Kecamatan Kebomas memiliki tingkat KDB tinggi sebesar $52 \%$ dari total desa/kelurahan di Kecamatan Kebomas, artinya 14 dari 21 desa/kelurahan yang memiliki kepadatan bangunan lebih dari $67 \%$. Kepadatan bangunan biasanya muncul dari adanya kepadatan penduduk pada suatu wilayah. Desa Giri adalah desa/kelurahan yang kepadatan penduduknya paling tinggi di
Kecamatan Kebomas. Semakin tinggi kepadatan penduduk biasanya berdampak pada semakin padatnya bangunan di sekitarnya. Hasil analisis penelitian ini didukung dengan penelitian Andriyanto (2013) yang mengungkapkan bahwa semakin padat bangunan pada suatu wilayah dapat menimbulkan potensi terjadinya rawan bencana kebakaran. Lebih jelasnya dapat dilihat pada Gambar 4. 
Linda Dwi Rohmadiani dan Rigen Adi Kowara: Tingkat Kawasan Rawan Lebakaran Sebagai Upaya Pencegahan dan Penenggulangan Kebakaran

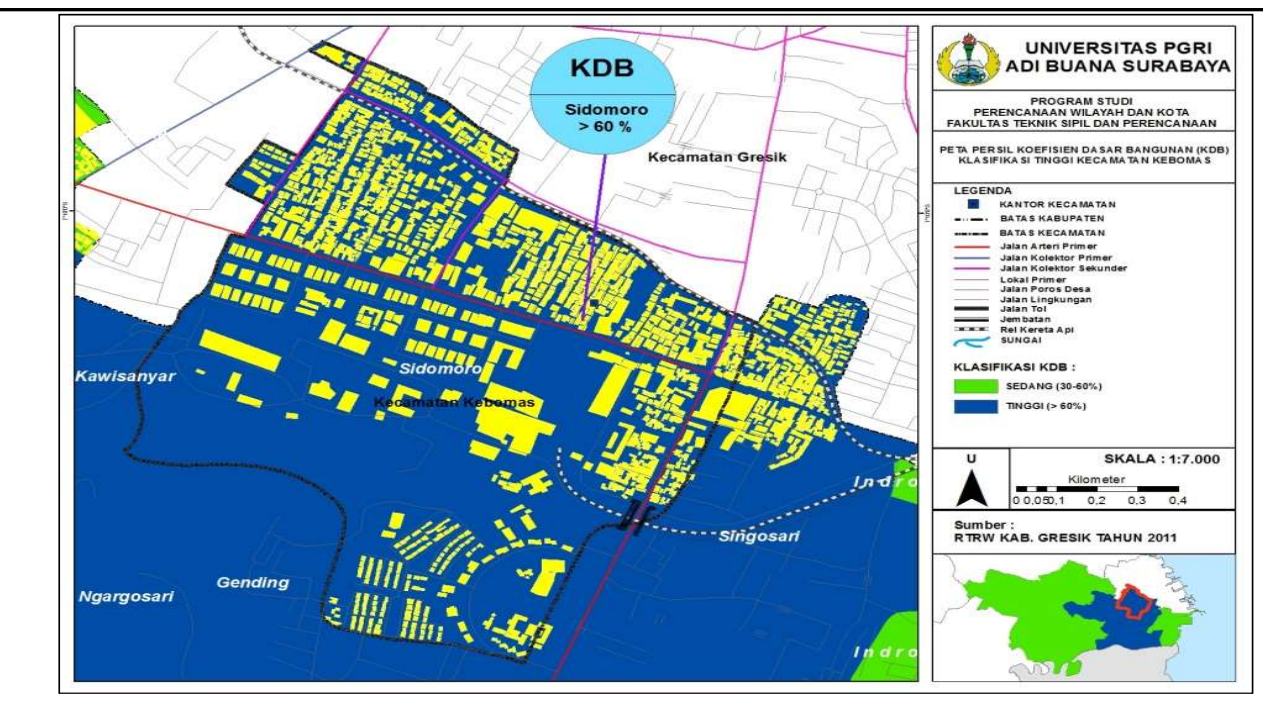

Gambar 4. Peta Persil Koefisien Dasar Bangunan Klasifikasi Tinggi di Kelurahan Sidomoro Tahun 2017

\section{5) Koefisien Lantai Bangunan (KLB)}

Sebagian besar desa/kelurahan di Kecamatan Kebomas memiliki tingkat KLB rendah sebesar $81 \%$ dari total desa/kelurahan di Kecamatan Kebomas, artinya 17 dari 21 desa/kelurahan yang memiliki ketinggian bangunan rendah, yaitu jumlah lantai bangunan maksimal 4 lantai sedangkan hanya ada 1 desa/kelurahan yang memiliki ketinggian bangunan tinggi adalah Desa Kembangan dengan rata-rata lantai bangunan 1-10 lantai, dimana rata-rata terdapat bangunan perkantoran dan kantor pemerintahan. Lebih jelasnya dapat dilihat pada Gambar 5.
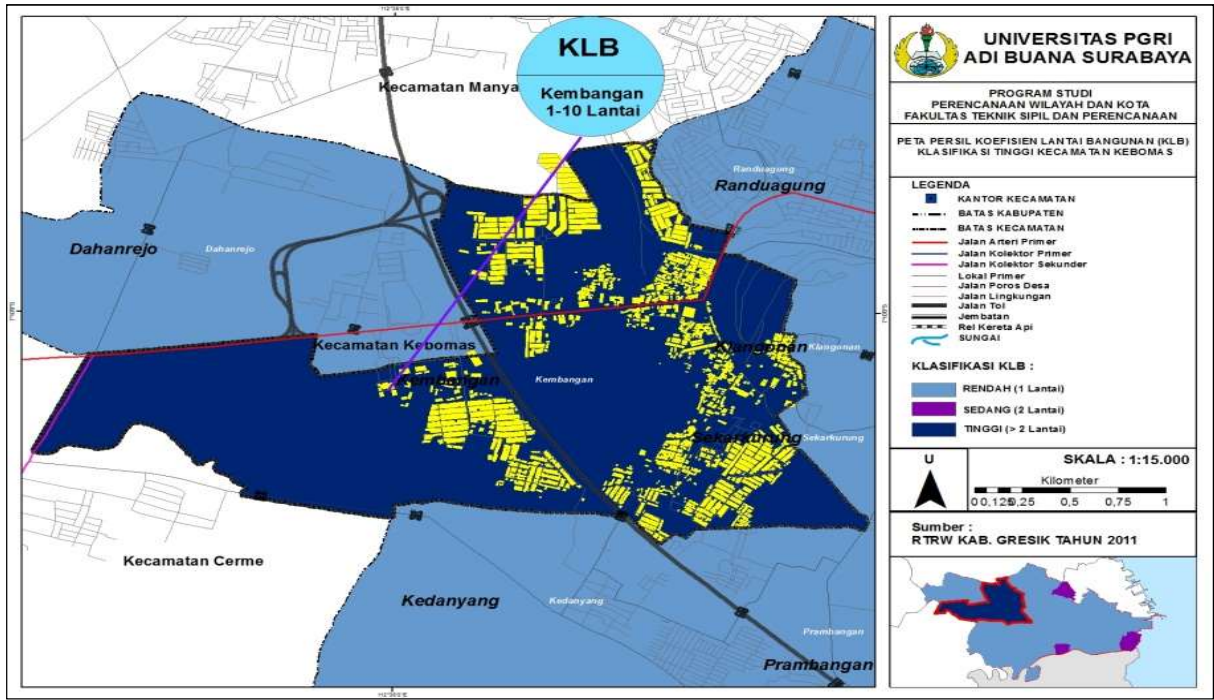

Gambar 5. Peta Persil Koefisien Lantai Bangunan Klasifikasi Tinggi di Desa Kembangan Tahun 2017 
6) Jarak Lokasi Sumber Air Terdekat

Hasil analisis jarak lokasi sumber air terdekat di Kecamatan Kebomas yang disesuaikan dengan Permen PU No. 20/PRT/M/2009 mengenai waktu tanggap (response time), dapat dilihat keseluruhan desa/kelurahan di Kecamatan Kebomas berjarak dekat dengan titik lokasi sumber air. Titik lokasi sumber air, baik alami maupun buatan serta lokasi hidran yang digunakan dalam penanggulangan bencana kebakaran berdasarkan hasil observasi lapangan dengan petugas pemadam kebakaran banyak terdapat embung serta sungai yang melintas yaitu Kali Lamong. Di setiap desa/kelurahan terdapat embung yang menyebar merata di seluruh wilayah Kecamatan Kebomas.

Hal tersebut didukung dengan fasilitas air yang digunakan pemadam kebakaran tidak mengalami kendala. Pada saat musim kemarau, stok air dalam tangki mobil pemadam kebakaran selalu kondisi sudah berisi full air, bahan bakar mesin, dan personil. Sehingga ketika ada insiden dalam pengambilan air akan menyesuaikan pada lokasi terjadinya kebakaran. Apabila titik lokasi sumber air berada di sekitar permukiman warga, maka pemadam kebakaran akan menggunakan sumber air tersebut atas ijin warga setempat. Selain Kali Lamong yang melewati 5 desa di Kecamatan Kebomas, titik lokasi sumber air terdekat di wilayah Kecamatan Kebomas adalah Kawasan Industri Gresik (KIG) yang berada di dekat Telaga Ngipik, Desa Randuagung. Hasil analisis deskriptif tersebut dapat dikatakan tidak ada satupun desa/kelurahan yang berjarak lebih dari $3,32 \mathrm{~km}$ dari titik lokasi sumber air. Lebih jelasnya dapat dilihat pada Gambar 6 .

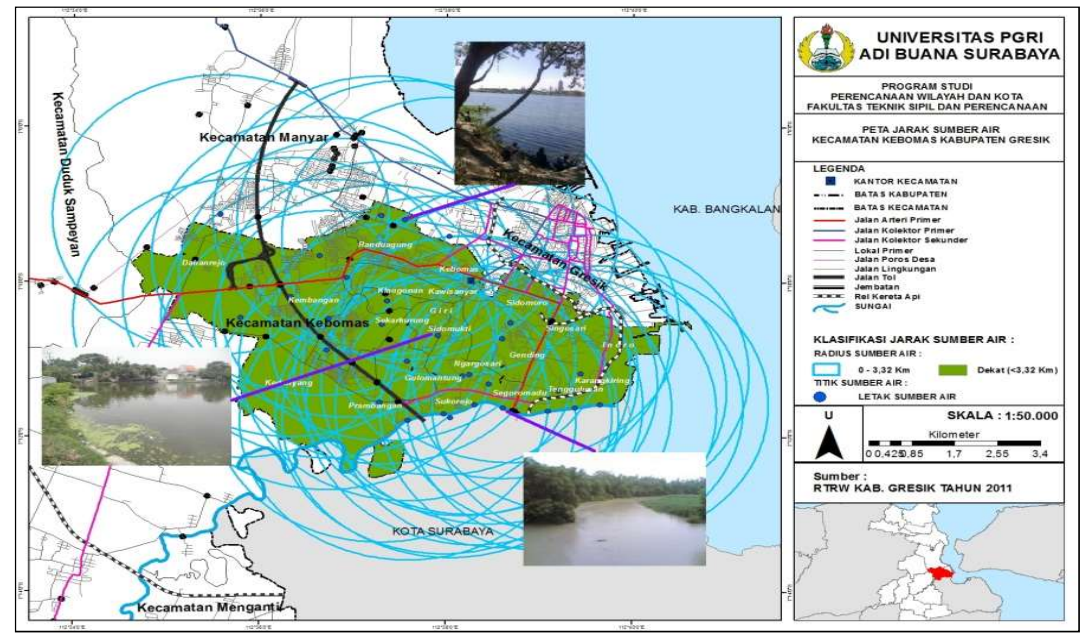

Gambar 6. Peta Analisis Jarak Sumber Air Terdekat di Kecamatan Kebomas Tahun 2017

\section{7) History Kebakaran}

History kebakaran atau kejadian kebakaran merupakan faktor pemicu terjadinya bencana kebakaran. Semakin tinggi atau semakin sering kejadian dalam suatu desa/kelurahan, maka semakin tinggi pula terjadinya kebakaran di masa yang akan datang. Sehingga desa/kelurahan yang sering terjadi kebakaran, dapat dikatakan sebagai kawasan yang rawan berdasarkan faktor pemicu kejadian kebakaran (Andriyanto, 2013).
Hasil analisis berdasarkan tren history kebakaran di Kecamatan Kebomas menunjukkan tahun 2012 sampai dengan tahun 2016 telah terjadi 324 kejadian kebakaran dengan rata-rata 64,8 atau 65 kejadian tiap tahunnya. Namun, dalam 5 tahun terakhir kejadian kebakaran di Kecamatan Kebomas mengalami penurunan sebesar 74\%. Data kejadian kebakaran dari Dinas Pekerjaan Umum bidang pemadam kebakaran menyebutkan jumlah kejadian 
Linda Dwi Rohmadiani dan Rigen Adi Kowara: Tingkat Kawasan Rawan Lebakaran Sebagai Upaya Pencegahan dan Penenggulangan Kebakaran

\begin{tabular}{lll}
\hline kebakaran pada masing-masing & Kebomas sedangkan hanya ada 1 \\
desa/kelurahan di Kecamatan Kebomas. & desa/kelurahan yang memiliki tingkat \\
Data yang terkumpul menunjukkan & bahaya sangat tinggi atau sebesar 5\% dari \\
desa/kelurahan yang mengalami jumlah & total desa/kelurahan di Kecamatan \\
kejadian paling tinggi selama kurun waktu & Kebomas, yaitu Desa Kembangan. Lebih \\
2012-2016 adalah Desa Kembangan dengan & jelasnya dapat dilihat Gambar 7.
\end{tabular}
jumlah 69 kejadian atau sebesar $21 \%$ dari total kejadian kebakaran di Kecamatan

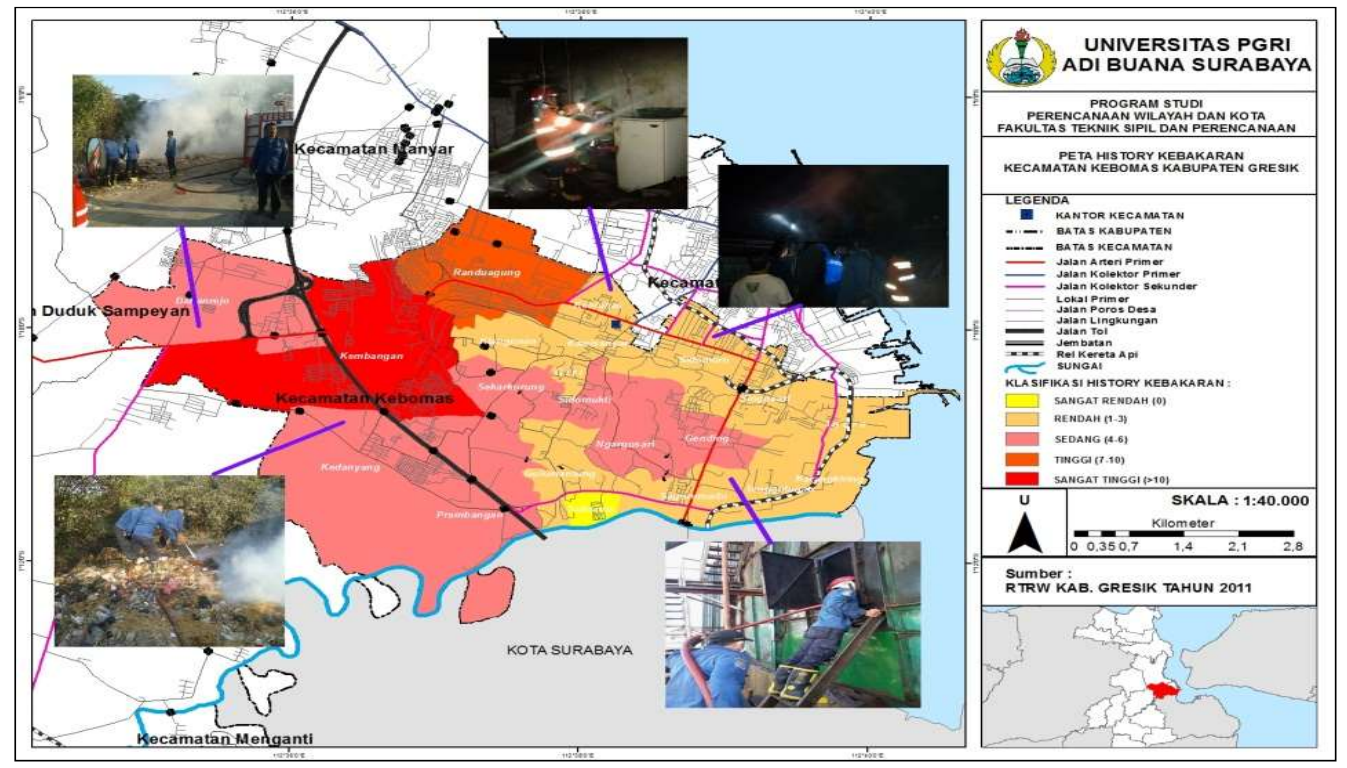

Gambar 7. Peta Analisis Tren History Kebakaran di Kecamatan Kebomas Tahun 2017

\section{8) Aksesibilitas Menuju Kawasan \\ Rawan Kebakaran}

Hasil analisis menunjukkan kondisi akses jalan di Kecamatan Kebomas sebagian besar digolongkan klasifikasi sedang sebesar $81 \%$ dari jumlah desa/kelurahan di Kecamatan Kebomas. Sehingga dapat dikatakan kondisi eksisting akses jalan di 17 desa/kelurahan, antara lain :

a) Jalan Arteri Primer: dilintasi sedikit jalan arteri primer; lebar jalan 6-15 meter; perkerasan aspal; kondisi baik

b) Jalan Kolektor Primer: lebar jalan 6-8 meter; perkerasan aspal dan paving; kondisi baik c) Jalan Kolektor Sekunder: lebar 6 meter; perkerasan paving, sebagian masih batu/tanah; kondisi baik

d) Jalan Lingkungan: lebar 4 meter; perkerasan paving, sebagian masih batu/tanah; kondisi baik

Desa Sekarkurung menjadi satusatunya desa/kelurahan yang akses jalannya buruk sehingga sulit dicapai oleh kendaraan pemadam kebakaran. Lebih jelasnya dapat dilihat pada Gambar 8 . 
Linda Dwi Rohmadiani dan Rigen Adi Kowara: Tingkat Kawasan Rawan Lebakaran Sebagai Upaya Pencegahan dan Penenggulangan Kebakaran

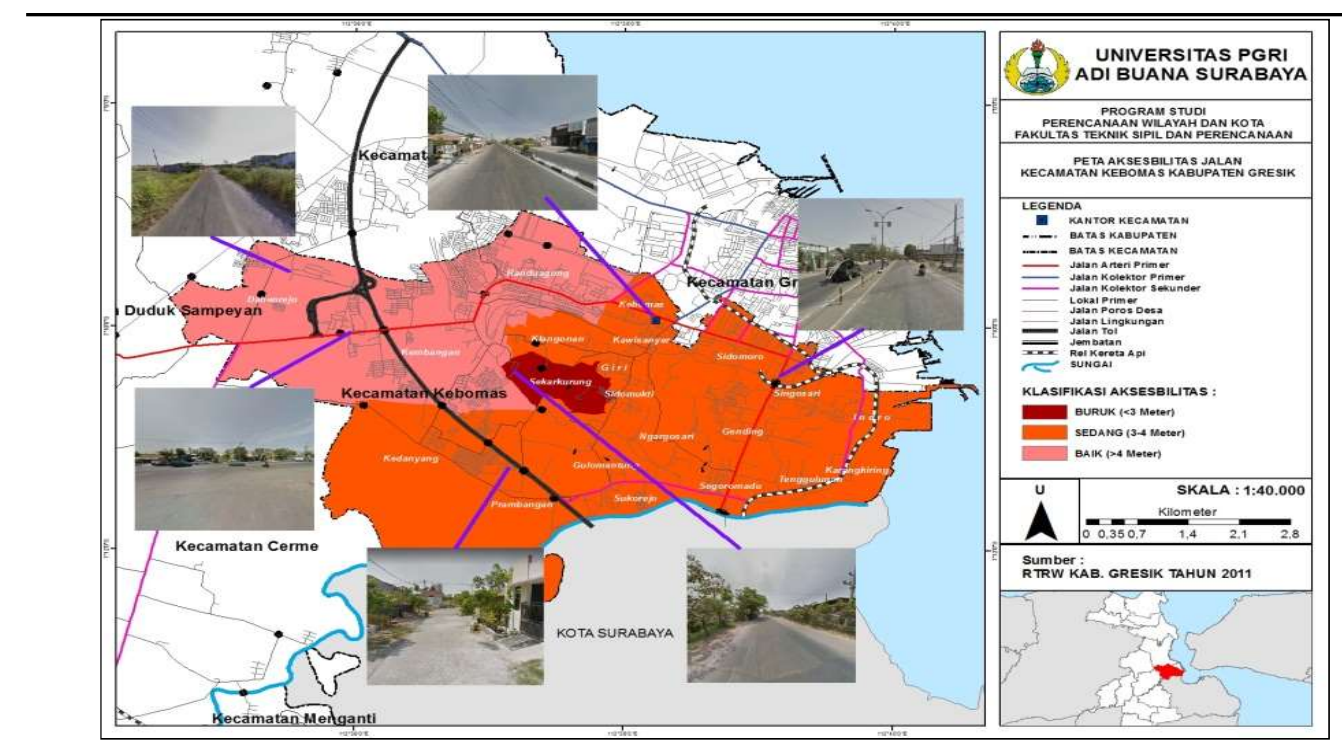

Gambar 8. Peta Analisis Aksesibilitas Menuju Kawasan Rawan Kebakaran di Kecamatan Kebomas Tahun 2017

\section{9) Jarak Pos PMK Eksisting Menuju Kawasan Rawan Kebakaran}

Hasil analisis yang disesuaikan dengan Peraturan Menteri Pekerjaan Umum Nomor 20/PRT/M/2009 mengenai waktu tanggap (response time), didapatkan pos pemadam kebakaran yang dimiliki oleh Kecamatan Kebomas dengan radius pelayanannya dapat menjangkau sebagian desa/kelurahan di Kecamatan Kebomas.

Lokasi pos pemadam kebakaran yang tersebar di Kecamatan Kebomas berada pada jangkauan maksimal 2,5 km, yaitu terdapat 11 desa/kelurahan atau sebesar $52 \%$ dari total desa/kelurahan di Kecamatan Kebomas. Lebih jelasnya dapat dilihat pada Gambar 9.

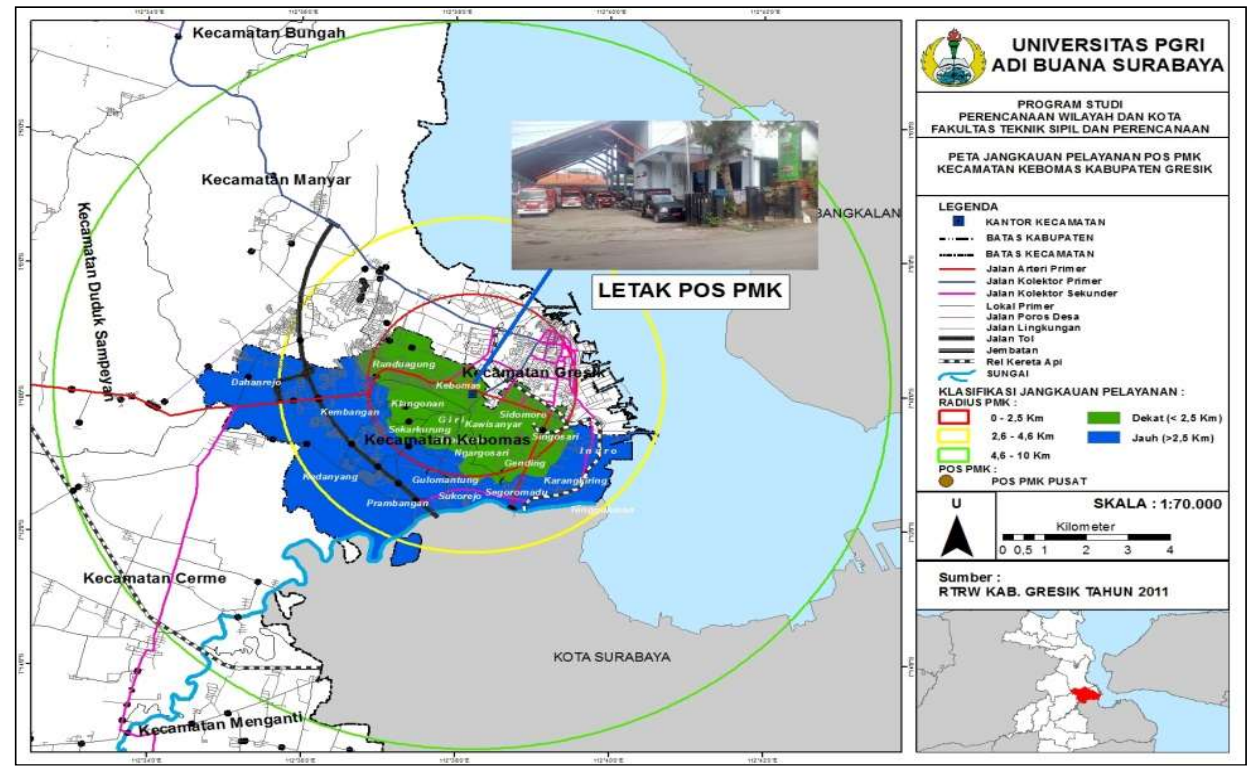

Gambar 9. Peta Analisis Aksesibilitas Menuju Kawasan Rawan Kebakaran di Kecamatan Kebomas Tahun 2017 
Linda Dwi Rohmadiani dan Rigen Adi Kowara: Tingkat Kawasan Rawan Lebakaran Sebagai Upaya Pencegahan dan Penenggulangan Kebakaran

\section{0) Proporsi Luas Kawasan \\ Terbangun Terhadap Luas Total Kawasan Rawan Kebakaran}

Hasil pemetaan proporsi luas kawasan terbangun terhadap luas total kawasan rawan kebakaran di Kecamatan Kebomas menunjukkan kawasan terbangun di Kecamatan Kebomas memiliki presentase $30-45 \%$, yaitu terdapat 7 desa/kelurahan atau 33\% dari total desa/kelurahan di Kecamatan Kebomas. Luas kawasan terbangun di Kecamatan Kebomas meliputi luas kawasan permukiman, luas perindustrian, luas sarana perdangan-jasa, dan luas sarana pelayanan umum. Hal ini dapat diartikan bahwa
Kecamatan Kebomas didominasi oleh kawasan tidak terbangun dengan presentase $55-70 \%$ yang meliputi sarana Ruang Terbuka Hijau (RTH), persawahan, perkebunan, dan pekarangan.

Hasil analisis deskriptif tersebut menunjukkan hanya ada 3 desa/kelurahan di Kecamatan Kebomas yang memiliki proporsi kawasan terbangun lebih dari $75 \%$ dimana proporsi tersebut dapat menjadi potensi terjadinya bencana kebakaran. Peta analisis proporsi luas kawasan terbangun terhadap luas total kawasan rawan kebakaran di Kecamatan Kebomas dapat dilihat pada Gambar 10.

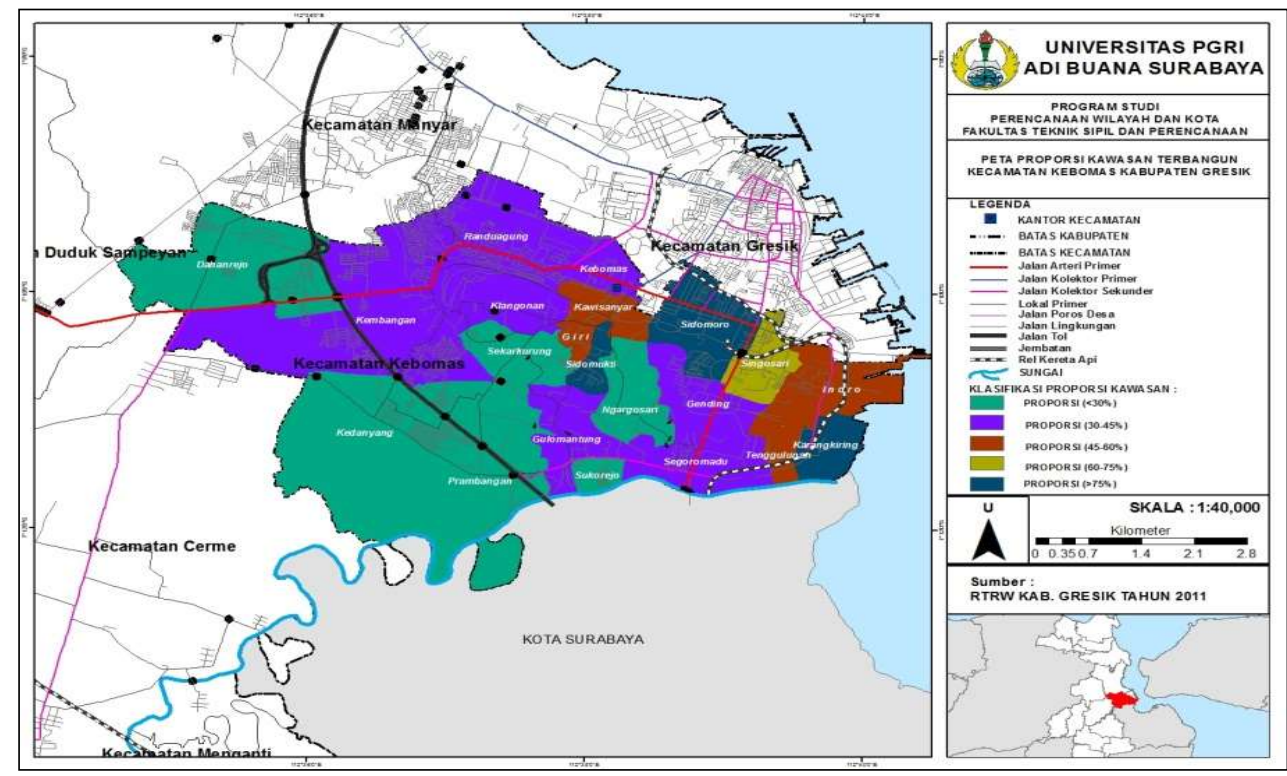

Gambar 10. Peta Analisis Proporsi Luas Kawasan Terbangun Terhadap Luas Total Kawasan Rawan Kebakaran di Kecamatan Kebomas Tahun 2017

\section{b. Penilaian Tingkat Risiko Kawasan Rawan Kebakaran di Kecamatan Kebomas \\ Penilaian kawasan berpotensi risiko} kebakaran di Kecamatan Kebomas ini merupakan lanjutan dari identifikasi potensi terjadinya kebakaran berdasarkan faktor pemicunya kebakaran di Kecamatan Kebomas yang telah dilakukan sebelumnya. Hasil dari analisis sebelumnya yang berupa penilaian terhadap variabel-variabel pemicu kebakaran dari hasil analisis deskriptif akan dilakukan analisis dengan pembobotan untuk mengetahui tingkat risiko bencana kebakaran pada setiap desa/kelurahan di Kecamatan Kebomas. Berdasarkan datadata pada seluruh desa/kelurahan di Kecamatan Kebomas, setiap desa/kelurahan memiliki nilai sub variabel yang mempengaruhi tingkat risiko bencana kebakaran yang beragam sehingga diperlukan pengelompokkan berdasarkan tingkat nilai risiko kebakaran agar mudah dalam upaya pencegahan dan penanggulangan 
Berdasarkan penentuan tingkat risiko

kebakaran di Kecamatan Kebomas menunjukkan seluruh desa/kelurahan di Kecamatan Kebomas tidak memiliki tingkat risiko kebakaran tinggi. Sebagian besar desa/kelurahan di Kecamatan Kebomas termasuk pada kawasan dengan tingkat risiko sedang yaitu $62 \%$ dari total desa/kelurahan di Kecamatan Kebomas. Sisanya hanya kawasan dengan tingkat risiko kebakaran rendah yaitu $38 \%$ atau ada 8 desa/kelurahan. Lebih jelasnya dapat dilihat pada Tabel 3 dan Gambar 11.

Tabel 5. Pemetaan Tingkat Risiko Kebakaran di Kecamatan Kebomas Tahun 2017

\begin{tabular}{lll}
\hline No $\quad$ Klasifikasi & \multicolumn{1}{c}{ Desa/Kelurahan } \\
\hline & & Sukorejo \\
& & Segoromadu \\
& & Tenggulunan \\
& & Karangkiring \\
& & Singosari \\
$1 . \quad$ Sedang & Sidomoro \\
& & Gending \\
& & Ngargosari \\
& & Sidomukti \\
& & Giri \\
& & Sekarkurung \\
& & Kembangan \\
& & Kebomas \\
& & Kedanyang \\
& & Prambangan \\
& & Gulomantung \\
2. & Rendah & Indro \\
& & Kawisanyar \\
& & Klangonan \\
& & Dahanrejo \\
& & Randuagung \\
\hline
\end{tabular}

Sumber: Hasil Analisis, 2017

\section{1) Kawasan dengan Tingkat Risiko Sedang}

Kawasan dengan tingkat risiko sedang di Kecamatan Kebomas berada pada Desa Sukorejo, Desa Segoromadu, Kelurahan Tenggulunan, Desa Karangkiring, Kelurahan Singosari, Kelurahan Sidomoro, Kelurahan Gending, Kelurahan Ngargosari, Kelurahan
Sidomukti, Desa Giri, Desa Sekarkurung, Desa Kembangan, dan Kelurahan Kebomas. Faktor utama yang mempengaruhi kawasan ini termasuk dalam tingkat risiko sedang karena kawasan-kawasan tersebut merupakan kawasan dengan fungsi hunian, perdagangan-jasa, dan industri, dimana kuantitas dan kandungan bahan mudah terbakarnya juga tinggi. Hal ini diperparah dengan Koefisien Dasar Bangunan (KDB) yang tinggi pula menandakan kepadatan bangunan pada kawasan tersebut tinggi menyebabkan sulutan api yang muncul akan lebih mudah menjalar, potensi bencana kebakaran akan semakin besar. Namun, kondisi lebar jalan di kawasan ini sudah dapat dikatakan baik sehingga mudah dilalui mobil pemadam kebakaran. Titik lokasi sumber air dan keberadaan pos Petugas Pemadam Kebakaran (PMK) di wilayah Kecamatan Kebomas juga masuk radius pelayanan pemadam kebakaran.

\section{2) Kawasan dengan Tingkat Risiko Rendah}

Daerah dengan tingkat risiko rendah yang berada di Kecamatan Kebomas berada di Desa Kedanyang, Desa Prambangan, Desa Klangonan, Kelurahan Indro, Desa Randuagung, Kelurahan Gulomantung, Kelurahan Kawisanyar, dan Desa Dahanrejo. Kawasan-kawasan tersebut umumnya merupakan daerah perumahan dengan konstruksi bangunan menggunakan bahan batu bata dan tembok modern, selain itu juga masih terdapat lahan yg diperuntukkan untuk Ruang Terbuka Hijau (RTH), pekarangan, dan lahan kosong sehingga kecil kemungkinan terjadi kebakaran di kawasan ini, namun tentu saja perlu waspada karena bencana kebakaran bisa datang baik faktor alam dan non alam.

Umumnya kawasan ini cukup mudah diakses oleh mobil pemadam kebakaran dan merupakan kawasan jauh dari permukiman dengan kepadatan penduduk tinggi, dan tentunya terdapat titik lokasi sumber air terdekat yaitu Kali Lamong yang melewati Desa Kedanyang dan Desa Prambangan sehingga memudahkan petugas pemadam kebakaran mengambil air apabila stok air habis. 
Linda Dwi Rohmadiani dan Rigen Adi Kowara: Tingkat Kawasan Rawan Lebakaran Sebagai Upaya Pencegahan dan Penenggulangan Kebakaran

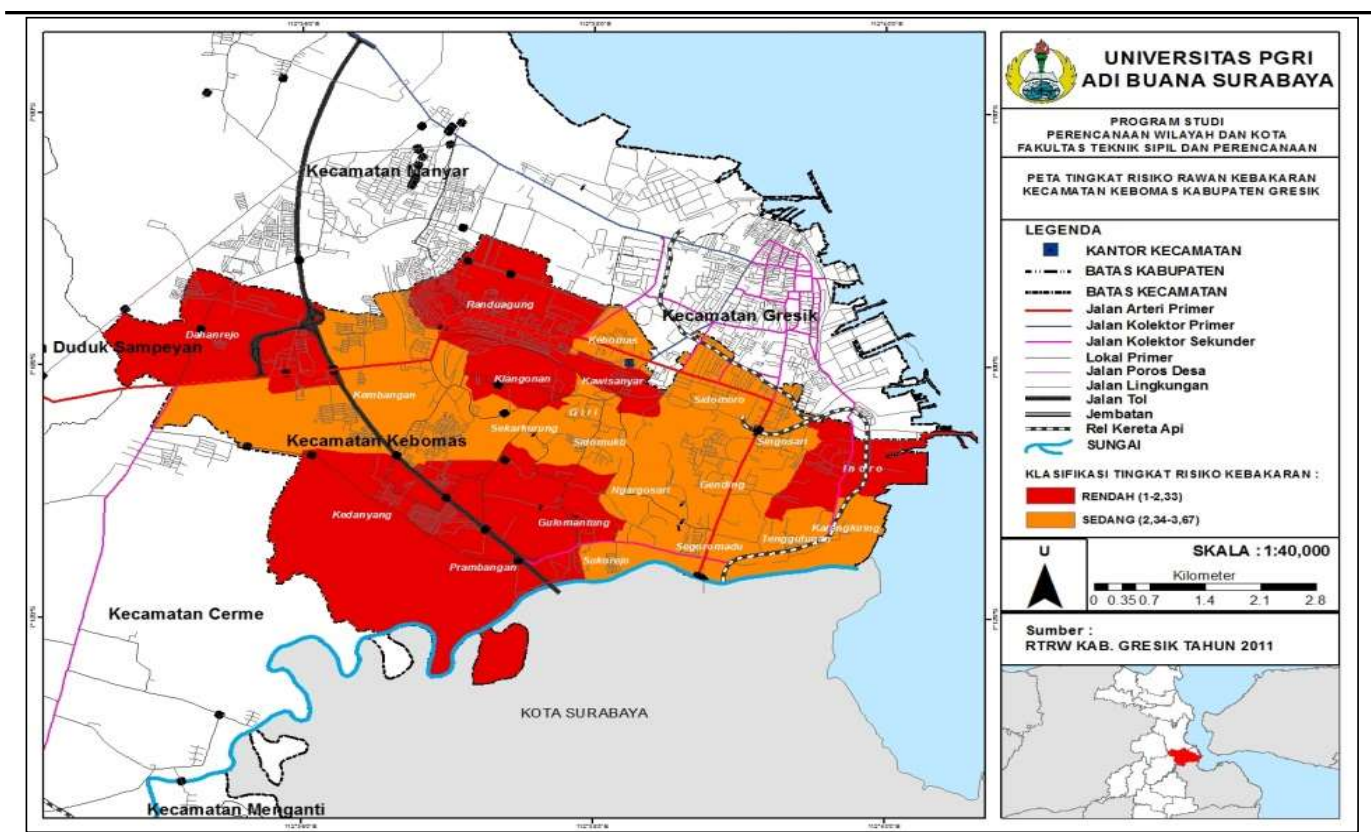

Gambar 11. Peta Analisis Tingkat Risiko Kawasan Rawan Kebakaran di Kecamatan Kebomas Tahun 2017

\section{KESIMPULAN}

Berdasarkan hasil analisis maka dapat disimpulkan bahwa tingkat risiko bencana kebakaran di Kecamatan Kebomas terbagi menjadi 2 kawasan yaitu sebagai berikut : Kawasan tingkat risiko sedang dengan nilai rentang 2,33 - 3,67 berada pada Desa Sukorejo, Desa Segoromadu, Kelurahan Tenggulunan, Desa Karangkiring, Kelurahan Singosari,
Kelurahan Sidomoro, Kelurahan Gending, Kelurahan Ngargosari, Kelurahan Sidomukti, Desa Giri, Desa Sekarkurung, Desa Kembangan, dan Kelurahan Kebomas. Kawasan tingkat risiko rendah pada rentang 1-2,33 berada pada Desa Kedanyang, Desa Prambangan, Desa Klangonan, Kelurahan Indro, Desa Randuagung, Kelurahan Gulomantung, Kelurahan Kawisanyar dan Desa Dahanrejo.

\section{UCAPAN TERIMA KASIH}

Penelitian ini mendapatkan dukungan dari laboratorium Perencanaan Wilayah dan Kota dan laboran program studi Perencanaan Wilayah dan Kota.

\section{DAFTAR PUSTAKA}

Anonim. (2016). Rencana Induk Sistem Proteksi Kebakaran Gresik Kota. Gresik: Dinas PU Kabupaten Gresik.

Anonim. (2011). Rencana Induk Sistem Proteksi Kebakaran Kota Muara Enim. Palembang: Kementerian PU Cipta Karya SNVT PBL Sumatera Selatan.

Anonim. (2011). Peraturan Daerah Kabupaten Gresik No.8 Tahun 2011 tentang Rencana Tata Ruang Wilayah Kabupaten Gresik Tahun 2010-2030. Gresik.

Anonim. (2009). Peraturan Menteri Pekerjaan Umum No. 20/PRT/M/2009 tentang Pedoman Teknis Manajemen Proteksi Kebakaran di Perkotaan. Jakarta: Penerbit PU.

Andriyanto, H. (2013). Pemetaan Potensi dan Resiko Kebakaran di Kota Surakarta. Skripsi. Surakarta: Program Perencanaan Wilayah dan Kota Universitas Sebelas Maret.

Dwijayanti.(2008). Mitigasi Bencana Kebakaran di Permukiman Padat Kecamatan Bojongloa Kaler (Studi Kasus: Kelurahan Babakan Asih dan Kelurahan Jamika). Skripsi. Bandung: Program Perencanaan Wilayah dan Kota Institut Teknologi Bandung. 
Linda Dwi Rohmadiani dan Rigen Adi Kowara: Tingkat Kawasan Rawan Lebakaran Sebagai Upaya Pencegahan dan Penenggulangan Kebakaran

Indrawan, S. M. (2013). Sistem Manajemen Pencegahan Kebakaran Gedung Tinggi: https://www.academia.edu/8277580/Sistem_Manajemen_Pencegahan_Kebakaran_Gedung Tinggi. Dipetik Desember 23, 2016

Notohadinegoro, T. (2006). Pembakaran dan Kebakaran Lahan. Universitas Gadjah Mada.

Pradipta. 2016. Perencanaan Pemasangan Alat Pemadam Api Ringan di Rumah Sakit Pendidikan Universitas Brawijaya Malang Gedung C. Skripsi. Surabaya: Universitas Airlangga.

Widyantoro, B. A. (2016). Analisis Tingkat Resiko Bencana Kebakaran Di Kecamatan Mariso Kota Makassar Berbasis Sistem Informasi Gegrafis (SIG). Jurnal Perencanaan Wilayah dan Kota, 94-102. Makassar: UIN Alauddin Makassar.

44 Jurnal Teknik WAKTU Volume 17 Nomor 01 - Januari 2019 - ISSN: 1412:1867 